\title{
Properties of Emulsified Meat Systems
}

\author{
E.V. Tsaregorodtseva ${ }^{1}$ T.V. Kabanova ${ }^{1}$, M.V. Dolgorukova ${ }^{1}$, E.A. Savinkova ${ }^{1}$, Yu.G. Krysenko², \\ I.S. Ivanov², V.A. Arsagov³, M.S. Gugkaeva ${ }^{3}$, Z.R. Tsugkieva ${ }^{3}$ and I.V. Pukhaeva ${ }^{3}$ \\ ${ }^{1}$ Mari State University, Lenin Square Yoshkar-Ola city, 424000, Russia. \\ ${ }^{2}$ Izhevsk State Agricultural Academy, Studentskaya street 11, Izhevsk city, 426069, Russia. \\ ${ }^{3}$ Gorsky State Agrarian University, Kirova street 37, Vladikavkaz city, 362040, Russia. \\ Corresponding author email: Smolentsev82@mail.ru
}

\section{ABSTRACT}

Proteins of muscle tissue affect not only the nutritional and biological value of meat, but also predetermine the condition of physico-chemical, structural-mechanical and technological parameters of raw materials (stickiness, viscosity, water binding capacity, pH, etc.) and finished products (juiciness, delicacy, output). They are different in structure, biological functions, physicochemical indicators, including solubility. Using sequential extraction of muscle proteins with water, saline and alkaline it is possible to obtain different protein fractions. Differentiation of proteins by solubility (watersoluble, soluble in salts, alkaline-soluble, albumins, globulins), fractional composition (sarcoplasmic, myofibrillar and connective tissue), peculiarities of the biochemical structure (high-grade and inferior). Protein extracts of muscle tissue of wild and domestic animals obtained during sequential extraction are used to quantify the protein content of a certain fraction, as well as to research the properties of proteins.In this scientific article the comparative analysis of functional and technological emulsions properties of cooked sausages is given. Cooked sausages are manufactured according to the national standard. Hydrated rice and flax flour formulations in a volume of 7\% were used instead of semigreasy pork. The rheological properties of cooked sausages' meat emulsions have been studied. The vegetable ingredients addition into the formulation of cooked sausages has been justified in order to stabilize the protein-in-oil emulsion.

\section{KEY WORDS: MEAT, QUALITY, EVALUATION, EXAMINATION, RESEARCH}

\section{INTRODUCTION}

Scientists have been working on the cooked sausages manufacture with an ideal combination of taste qualities, organoleptic characteristics, high food and biological value and also in the price bracket of economy class. Rice and flax flour adding in the product content helps to improve functional and technological properties of cooked sausages and also to reduce the price (Kabanova et al., 2020).

From the muscle tissue of meat, proteins can be isolated and divided due to their different solubility in different solutions. Soluble proteins are mainly found in the

Biosc Biotech Res Comm P-ISSN: 0974-6455 E-ISSN: 2321-4007

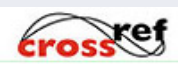

Identifiers and Pagination

Year: 2021 Vol: 14 No (9) Special Issue

Pages: $96-100$

This is an open access article under Creative

Commons License Attribn 4.0 Intl (CC-BY). DOI: http://dx.doi.org/10.21786/bbrc/14.9.21 sarcoplasm of muscle fibers, and soluble salts form myofibrils. Insoluble protein fractions in water-salt solutions are conditionally called stroma proteins, which contain proteins of sarcolemma, nuclei and intracellular connective tissue proteins. Muscular proteins, according to their solubility, are divided into three groups myofibrillar (55\% of total proteins), sarcoplasmic (35\% of total proteins) and connective tissue proteins (3-5\% of total proteins) (Tsaregorodtseva et al., 2020).

Sarcoplasmic proteins: myogen, globulin X, myoalbumin, myoglobin - are located inside the membrane of muscle cells in the sarcoplasm and account for about 30-35\% of the total number of proteins in the muscle. These proteins are soluble in water or in solutions with a low ionic power (<0.6 millimole / cdm). Proteins of sarcoplasm are water soluble, mostly high-grade and well digested. This group of proteins also includes oxidative enzymes, heme pigments, glycolytic enzymes, which are responsible for glycolysis, and liposomal enzymes (Dolgorukova et al., 2018; Okhotnikov et al., 2020).
Article Information

Received: $11^{\text {th }}$ Apr 2021 ccepted after revision: $10^{\text {th }}$ June 2021 
Myofibrillar proteins, or salt-soluble proteins, are insoluble in water, but most of them are soluble in a solution of table salt with a concentration of more than $1 \%$. This group consists of approximately 20 individual proteins which are part of the myofibrils of the contractile muscle. Myofibrillar proteins include the contractile proteins myosin, actin and actomyosin, as well as regulatory proteins tropomyosin, troponin and alpha and beta actin. Myofibrillar proteins provide contractile muscle function (Kabanova et al., 2016; Kuzmina et al., 2020).

Connective tissue proteins of meat form a net that envelops the muscle fibers and pervades the entire muscle. Because of this, they serve as a frame that supports the structure of the muscle. These include proteins of sarcolemma and intramuscular connective tissue (collagen, elastin, reticulin, mucins, mucoids, lipoproteins, acidic and residual proteins). These proteins, except for collagen and elastin, can be extracted from muscle tissue with a $0.25 \%$ solution of $\mathrm{NaOH}$ (Kuzmina et al., 2018).

\section{MATERIAL AND METHODS}

Experimental data showed that rice flour has a gelforming capacity of $19.0 \mathrm{~g}$, and flax flour's gel-forming capacity is $17.0 \mathrm{~g}$, which corresponds to the level of soy protein isolators $(16 \mathrm{~g})$. Consequently, the ability of nutrient additives to gel formation affects the consistency of processed meat products, especially those which recipe contains a large amount of non-meat ingredients (fig. 1).

Figure 1: Functional and technological properties of rice and flax flour

Level of WBC and $F B C, \%$ and rice and flax

flour's ability to gel-formation, $g$

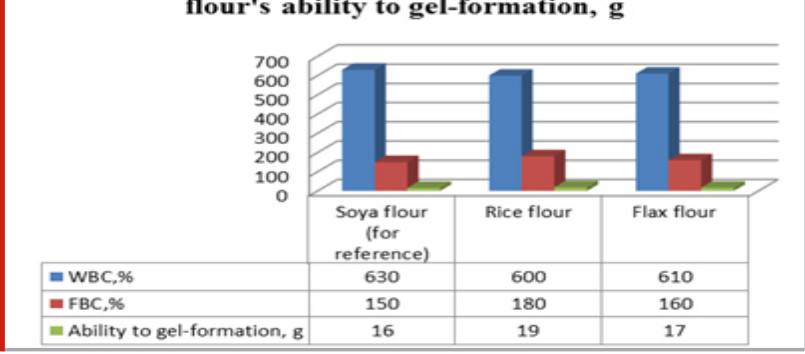

On the basis of the functional and technological properties' analysis it can be stated that rice and flax flour addition to the meat farce should improve WBC, FBC and gel-forming capacity of meat system.

Then loose sausage was made in the meat cutter according to the recipe:

Control: $25 \%$ of prime beef, $70 \%$ of semigreasy pork, $3 \%$ of egg, $2 \%$ of milk.

Experiment №1: 25\% of prime beef, 63\% of semigreasy pork, $7 \%$ of rice flour, $3 \%$ of egg, $2 \%$ of milk.

Experiment No2: 25\% of prime beef, 63\% of semigreasy pork, $7 \%$ of flax flour, $3 \%$ of egg, $2 \%$ of milk.

In the settings of technological laboratory, laboratories of biological safety of food systems and rheology of the chair of meat and dairy products technologies of Mari State University conducted the following laboratory researches:

- Water binding capacity was determined according to the Grau's compaction method modified by V.P. Volovinskaya, B. Y Kelman.

- Water retaining capacity of minced meat was determined by calculation after drying out hinges in the drying apparatus APS- 1 and calculation of the total humidity mass fraction.

- Fat-retaining capacity was determined after centrifugation of the minced meat samples in the eleometer and then calculated by the refraction index of the refractometer.

- Laboratory-scale plant for adhesiveness determination according to S. Tyszkiewicz was used to determine the minced meat's surface characteristics.

- Shift properties were determined by using consistometer.

\section{RESULT AND DISCUSSION}

Examination of the WBC level of the moist minced meat showed (table 1) that the Experiment No1 has WBC of $78,5 \pm 0,47 \%$ and the Experiment No2 has WBC of $77,4 \pm 0,32 \%$. These counts are bigger than in Control by $2,6 \pm 0,43 \%$ and $1,5 \pm 0,43 \%$ correspondingly $(\mathrm{P}<0,05)$. There was no significant difference between the Experiment №1 and the Experiment №2.

\begin{tabular}{|c|c|c|c|c|}
\hline \multirow[t]{2}{*}{ Groups } & \multicolumn{2}{|c|}{ Minced meat's WBC level } & \multicolumn{2}{|c|}{ Released product's WRC } \\
\hline & $\mathrm{M} \pm \mathrm{m}$ & $\mathrm{Cv}, \%$ & $\mathrm{M} \pm \mathrm{m}$ & $\mathrm{Cv}, \%$ \\
\hline Control & $75,9 \pm 0,43$ & 0,8 & $72,5 \pm 0,04$ & 0,1 \\
\hline Experiment $N \underline{0} 1$ & $78,5 \pm 0,47^{*}$ & 0,8 & $74,1 \pm 0,11^{* * *}$ & 0,2 \\
\hline Experiment $N \underline{\underline{o}} 2$ & $77,4 \pm 0,32^{*}$ & 0,6 & $73,6 \pm 0,21$ & 0,4 \\
\hline
\end{tabular}


Determination of released product's water retaining capacity (WRC) proved the hypothesis of the possibility of the larger proportion of moisture maintaining in a sausage link after heat-treating operation, as the Experiment $N \underline{0} 1$ had the largest rate of $74,1 \pm 0,11 \%$, which was bigger than in the Control by $1,6 \pm 0,04 \%$ $(\mathrm{P}<0,001)$. There was no significant difference between the Experiment №1 and the Experiment №2. It means that rice and flax flour addition contributed to WBC and WRC increase in comparison with Control. It is the result of the hydrophilic centers of rice and flax proteins' ability to bind and retain more water, increasing the proportion of loosely bound available moisture in raw minced meat and firmly bound moisture in the released product.

Rice flour addition contributed to the protein-in-oil emulsion stabilization in a greater degree than flax flour addition, because in the Experiment №1 WRC level of the released product was reliably higher in comparison with the Control by $1,6 \pm 0,04 \%(\mathrm{P}<0,001)$. In the Experiment No2 there was no significant difference on this indicator in comparison with the Control. At the same time, WRC indicators of test samples did not have significant differences, consequently, addition of 7\% hydrated rice and flax flour instead of semigreasy pork contributes to increase of minced meat's water binding capacity and released product's water retaining (fig.2).

Figure 2: Determination of minced meat's WBC and released product's WRC

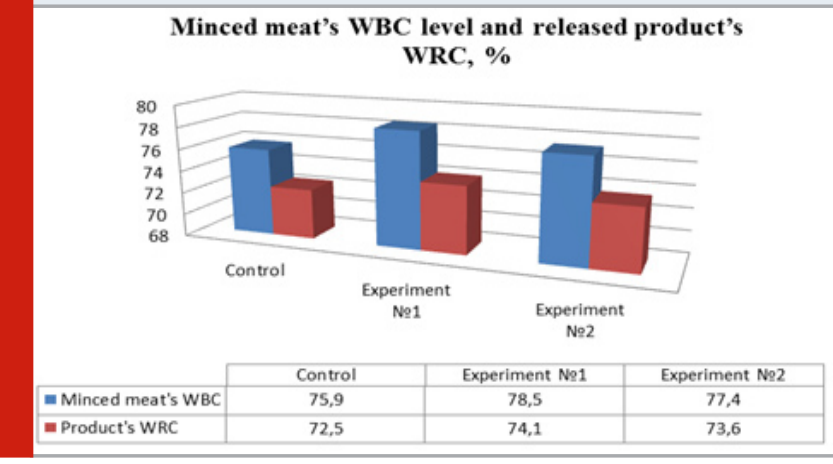

Table 2. Plasticity amount of minced meat

\begin{tabular}{|l|c|c|}
\hline \multirow{2}{*}{ Sample } & \multicolumn{2}{|c|}{ Plasticity amount, g/cm2 } \\
\hline \multirow{2}{*}{ Control } & $\mathrm{M}_{ \pm} \mathrm{m}$ & $\mathrm{Cv}, \%$ \\
\cline { 2 - 3 } & $10,20 \pm 0,07$ & 0,9 \\
\hline Experiment $N \underline{0} 1$ & $12,60 \pm 0,07^{*}$ & 0,8 \\
\hline Experiment $N \underline{0} 2$ & $15,43 \pm 0,11^{* *}$ & 0,9 \\
\hline
\end{tabular}

Variability of WBC and WRC indicators of control and test samples is insignificant, because Coefficient of variation $(\mathrm{CV})$ is less than $10 \%$. The most complete information about the quality and properties of minced meat systems which depend on the chemical composition and which are determined by the internal structure can be judged using rheological methods. One of the main structural and mechanical characteristics of the quality of minced meat is plasticity. Tenderness and succulence which determine taste of released minced products depend on plasticity (table 2).

Unlike emulsified greasy pork (Control), hydrated flax flour (Exp. No2) and rice flour (Exp.№1) have a gel texture and their consistency is less sticky. Consequently, while adding them into the cutter, they envelop and bind the muscle fibers and connective tissue components to a single matrix and they improve plasticity of the cutter mass (Fig. 3). Estimated data proves that plasticity indicator in Control is less than in test samples, particularly it is less by $2,4 \pm 0,07 \mathrm{~g} / \mathrm{cm} 2$ in Experiment №1 $(\mathrm{P}<0,05)$, and by $5,2 \pm 0,11 \mathrm{~g} / \mathrm{cm} 2 \quad(\mathrm{P}<0,01)$ in Experiment №22. It means that rice and flax flour usage in cooked sausage significantly increases minced meat's plasticity, making its consistency tight considerably.

Figure 3: Determination of minced meat's plasticity

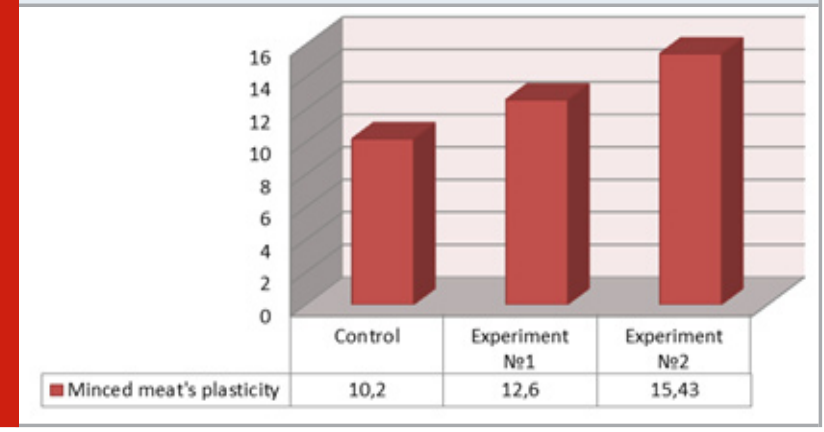

Variability of minced meat's plasticity both of control and test samples is insignificant because the Coefficient of variation is $<10 \%$. In the course of the conducted research the adhesion (stickiness) amount was also determined. Obtained data is presented in Table 3.

Emulsion of the Experiment №2 has the greatest adhesiveness, it is $445,26 \pm 18,37 \mathrm{~Pa}$, which is bigger than in Control by $112,35 \pm 28,4 \mathrm{~Pa}(\mathrm{P}<0,05)$ (PNC. 4). Emulsion of the Experiment №1 also takes precedence of Control on adhesiveness amount by $97,84 \pm 28,4 \mathrm{~Pa}$ $(P<0,05)$. There is no significant differences between Experiment №1 and Experiment №2. On this base, it can be concluded that addition of flax and rice flour has a direct impact on structural and mechanical properties of the product. The minced meat of test samples has the greatest binding (adhesive) capacity than a control sample, which determines elastic properties and the ability to form monolithic product. Variability of minced meat's viscosity both of control and test samples is insignificant because Coefficient of variation is less than $10 \%$.

High adhesion rates influenced the terminal share stress amount: Experiment №2 and Experiment №1 possessed the most strong properties of $264,73 \pm 2,81 \mathrm{~Pa}$ and 260,3 $\pm 0,67$ Pa correspondingly (Fig.5). Amounts of these test samples took precedence of Control by $84,3 \pm 0,64$ $\mathrm{Pa}$ and $79,9 \pm 0,64 \mathrm{~Pa}$ correspondingly $(\mathrm{P}<0,001)$. There 
is no significant difference between Experiment № 1 and Experiment №2.

It means that rice and flax flour added during the chopping process interacted with muscle proteins and fat-containing raw materials and tied up all minced meat's components. This contributed to thickening of protein-oil-fat emulsion, and meat system became stable (table 2). The variability of terminal share stress amount both of Control and test samples was insignificant, as the Coefficient of variation was less than $10 \%$. Observed data obtained during the study of mince meat's viscous properties using Brookfield viscometer showed that the most significant increase in minced meat's viscosity is observed during the addition of $7 \%$ flax flour of $389,53 \pm 22,71 \mathrm{Paxc}$ and of $7 \%$ rice flour of $373,03 \pm 16,47 \mathrm{Paxc}$, which is bigger than in Control by $63,9 \pm 5,66 \mathrm{~Pa} \times \mathrm{c}$ and 47,67 $\pm 5,66$ Paxc correspondingly $(\mathrm{P}<0,05)$ (table 2).

\begin{tabular}{|c|c|c|c|}
\hline Sample & $\begin{array}{l}\text { Adhesion } \\
\text { amount, } \mathrm{Pa} \\
\mathrm{M} \pm \mathrm{m}\end{array}$ & $\begin{array}{l}\text { Terminate shear } \\
\text { stress amount , Pa } \\
\quad \mathrm{M}_{ \pm \mathrm{m}}\end{array}$ & $\begin{array}{l}\text { Viscosity } \\
\text { Pa×c } \\
M_{ \pm m}\end{array}$ \\
\hline Control & $332,91 \pm 28,4$ & $180,40 \pm 0,64$ & $325,63 \pm 5,66$ \\
\hline Experiment $N \underline{0} 1$ & $430,75 \pm 7,70^{*}$ & $260,30 \pm 0,67^{* * *}$ & $373,03 \pm 16,47^{*}$ \\
\hline Experiment $N \underline{o} 2$ & $445,26 \pm 18,37^{*}$ & $264,73 \pm 2,81^{* * *}$ & $389,53 \pm 22,71^{*}$ \\
\hline
\end{tabular}

Figure 4: Adhesion index of examined samples

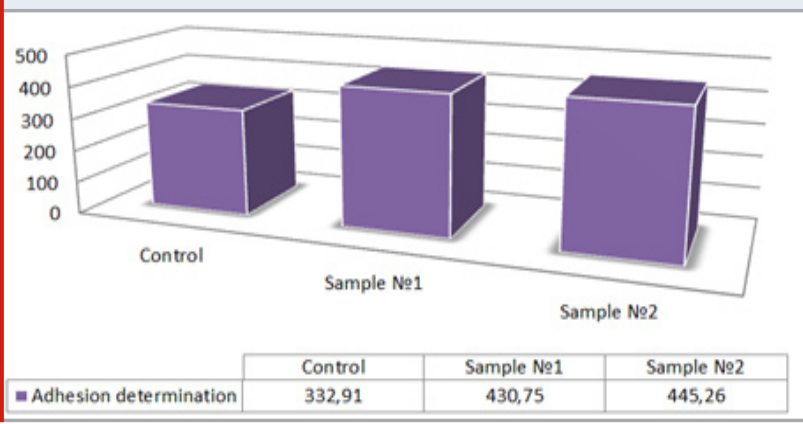

Figure 5: Terminal share stress amount

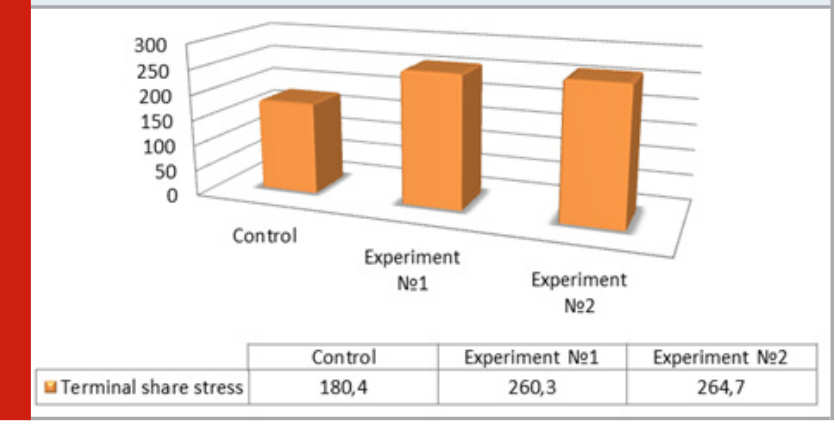

There was no significant difference between Experiment Non 1 and Experiment №2. It is explained by the fact that there is starch in the rice and flax composition and when heated it forms starch paste which promotes viscosity increase (Fig.6).

\section{CONCLUSION}

Addition of rice and flax flour contributed to increase in WBC and WRC by contrast to Control. It is the result of the hydrophilic centers of rice and flax proteins' ability to bind and retain more water, increasing the proportion
Figure 6: Determination of minced meat's viscosity

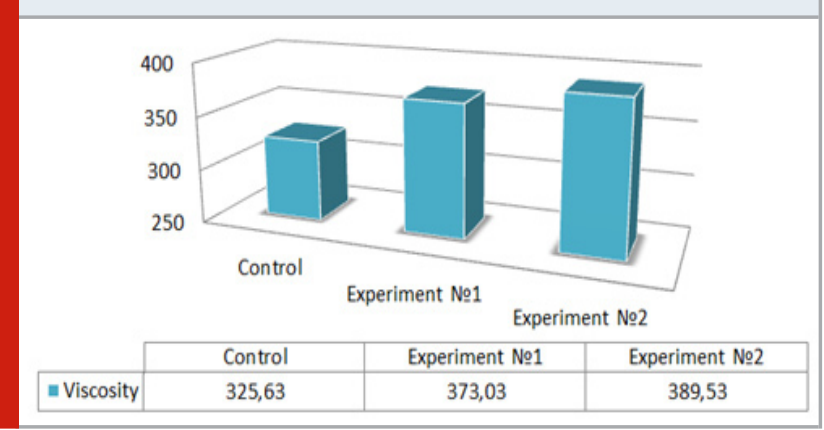

of loosely bound available moisture in raw minced meat and firmly bound moisture in the released product. Meat emulsion of test samples with 7\% rice and flax flour addition has high rheological properties, which makes the meat system more stable and contributes to forming sausage links into monolithic product.

Source of Funding: The authors declare that they have no funding support for this study.

Conflict of Interest: The authors declare that there is no known conflict of interest associated with this publication.

\section{REFERENCES}

Kabanova T.V., Dolgorukova M.V., Okhotnikov S.I., Tsaregorodtseva E.V., Smolentsev S.Yu., Savinkova E.A., Onegov A.V. 2020. The Influence of Fermented Mare's Milk Processing Under Pressure of Gaseous Nitrogen on the Quality of Koumiss, International Journal of Research in Pharmaceutical Sciences, 11(2): 23502354.

Tsaregorodtseva E.V., Kabanova T.V., Okhotnikov S.I., Dolgorukova M.V. 2020. Approaches to safety 
and quality of foodstuffs in the european union and Russia, IOP Conference Series: Earth and Environmental Science. conference proceedings. Krasnoyarsk Science and Technology City Hall of the Russian Union of Scientific and Engineering Associations: 32003.

Okhotnikov S.I., Kabanova T.V., Tsaregorodtseva E.V., Dolgorukova M.V. 2020. The use of laminaria in the manufacture of soft cheeses, IOP Conference Series: Earth and Environmental Science. conference proceedings. Krasnoyarsk Science and Technology City Hall of the Russian Union of Scientific and Engineering Associations: 32004

Dolgorukova M.V., Shuvalova E.G., Kabanova T.V., Tsaregorodtseva E.V., Okhotnikov S.I. 2018. The cultivation of kefir corns in cheese milk whey, Research Journal of Pharmaceutical, Biological and Chemical Sciences, 9(4): 1276-1280.

Kabanova T.V., Savinkova E.A., Okhotnikov S.I.,
Tsaregorodtseva E.V., Dolgorukova M.V., Shuvalova E.G. 2016. The influence and effect of treatment by pressure of gaseous nitrogen on the biotechnology and microbiological indicators of cow's milk, Research Journal of Pharmaceutical, Biological and Chemical Sciences. 7(2): 771-780.

Kuzmina N.N., Petrov O.Yu., Savinkova E.A. 2020. Influence of natural antioxidants on quality indicators of semi-finished products from meat of broilers, IOP Conference Series: Earth and Environmental Science. conference proceedings. Krasnoyarsk Science and Technology City Hall of the Russian Union of Scientific and Engineering Associations: 22074.

Kuzmina N.N., Petrov O.Y., Savinkova E.A., Guseva I.V. 2018. Effectiveness of effect of antioxidant of new generation on oxidizing processes in the containing collagen raw materials of the poultry-processing industry, IOP Conference Series: Materials Science and Engineering: 012004. 